\title{
Desenvolvimento sustentável nos discursos do Equador na AGNU
}

\author{
Sustainable development in the speeches of the Ecuador in the UNGA
}

\author{
Marcelino Teixeira Lisboa ${ }^{1}$
}

Karen Johana Bombón Pozo

\begin{abstract}
Resumo
Este texto apresenta os resultados da exploração, através da análise de conteúdo, dos discursos do Equador na Assembleia Geral das Nações Unidas (AGNU), entre 2007 e 2016, com o objetivo de verificar como o desenvolvimento sustentável esteve presente em tais pronunciamentos. É realizada uma abordagem quantitativa para verificar a presença e a frequência do tema nos discursos. Posteriormente, os textos são analisados em relação ao significado do desenvolvimento sustentável nos pronunciamentos, bem como a ligação com outros temas relevantes. Verificou-se que, no período analisado, o buen vivir como um modelo de desenvolvimento e o projeto Yasuní-ITT, que visava a preservação ambiental, estiveram diretamente relacionados com o enfoque do desenvolvimento sustentável. Além disso, o discurso apresentou diferentes ênfases e significados em distintos períodos ao longo dos dez anos considerados na análise. O texto apresenta um caráter muito mais exploratório do que analítico, mas permitiu captar diversas nuances da construção da visão equatoriana de desenvolvimento sustentável, durante os governos de Rafael Correa.
\end{abstract}

Palavras-chave: Desenvolvimento sustentável. Buen vivir. Equador. Yasuní-ITT.

\begin{abstract}
This text presents the results of the exploring of the speeches of Ecuador at the United Nations General Assembly (UNGA), between 2007 and 2016. The objective is to verify how sustainable development was present in such of the pronouncements. A quantitative approach is carried out to verify the presence and frequency of the theme in the speeches. After, the texts are analyzed in relation to the meaning of sustainable development in the pronouncements, as well as the connection with other relevant themes. It was verified that in the period analyzed, buen vivir as a development model and the Yasuní-ITT project, as a initiave for environmental preservation, were directly related to the sustainable development approach. In addition, the discourse presented different emphases and meanings in different periods during the ten years addressed in the analysis. The text presents a much more exploratory than analytical character, but allowed to capture several nuances of the construction of the vision of the Ecuador about sustainable development, during the governments of Rafael Correa. Keywords: Sustainable development. Buen vivir. Ecuador. Yasuní-ITT.

\footnotetext{
${ }^{1}$ Doutor em Ciência Política (UFRGS). Professor da Universidade Federal da Integração Latino Americana (UNILA). E-mail: marcelino.lisboa@unila.edu.br.

${ }^{2}$ Doutoranda em Estudos Internacionais pela Facultad Latinoamericana de Ciencias Sociales (FLACSO - Equador) Email: karen2_bp@hotmail.com.
} 


\section{Introdução}

Este texto apresenta os resultados da exploração, através da análise de conteúdo, dos discursos do Equador na Assembleia Geral das Nações Unidas (AGNU), entre 2007 e 2016, com o objetivo de verificar como o desenvolvimento sustentável esteve presente em tais pronunciamentos. O período em análise refere-se à fase dos três mandatos de Rafael Vicente Correa Delgado na presidência do país, entre 15 de janeiro de 2007 e 24 de maio de 2017.

O Equador passou a ter visibilidade em temas relacionados ao meio ambiente após a promulgação da Constituição de 2008, na qual consta, desde o seu preâmbulo, a ênfase em temas ligados à preservação do meio ambiente. Destaca o texto que "celebrando a la naturaleza, la Pacha Mama, de la que somos parte y que es vital para nuestra existencia [...], [d]ecidimos construir [u]na nueva forma de convivencia ciudadana, en diversidad y armonía con la naturaleza, para alcanzar el buen vivir, el sumak kawsay" (ECUADOR, 2008b, p. 15). O texto constitucional possui 23 artigos que tratam especificamente do buen vivir. O governo equatoriano, no período de Correa, enfatizou essa questão em diversos espaços internacionais, marcadamente após o Foro de Presidentes Sobre Mudanças Climáticas, realizado em 2007, no âmbito da Organização das Nações Unidas (ONU).

A maior atenção com a degradação da natureza e a preservação dos recursos naturais, por sua vez, como tema da agenda internacional em nível global, tem como principal referência temporal a Conferência de Estocolmo, realizada em junho de 1972. Após esse evento, o tema não saiu mais da agenda da política dos Estados, gerando diversas outras conferências, documentos e declarações, tais como a Resolução 42/186 da AGNU, de 1987, sobre desenvolvimento a partir de um ponto de vista ambiental, a Conferência Mundial do Meio Ambiente (Rio 92), a Conferência Mundial sobre Desenvolvimento Sustentável em 2002 e a Conferência Rio+20 em 2012 (HANDL, 2012).

A definição de desenvolvimento sustentável como "aquele que atende as necessidades do presente sem comprometer as possibilidades de as gerações futuras atenderem suas próprias necessidades" foi utilizada pela primeira vez pela Comissão de Meio Ambiente e Desenvolvimento da ONU, na 42 ${ }^{\text {a }}$ Sessão Ordinária da AGNU (ONU, 1987). Apesar do termo ter sido cunhado por esta comissão, a ideia de desenvolvimento sustentável é um desdobramento do que foi iniciado na Conferência de Estocolmo (HANDL, 2012).

Desde que passou a ser um tema relevante da agenda, o desenvolvimento sustentável passou também a fazer parte dos discursos dos Estados em foros internacionais como a Assembleia Geral da ONU. Ao longo das três décadas e meia que separam a Conferência de Estocolmo e o início do primeiro mandato de Rafael Correa como presidente do Equador, as questões ambientais e o desenvolvimento sustentável ganharam cada vez mais espaço nos discursos oficiais. Sendo assim, 
pela ênfase dada à preservação da natureza na Constituição equatoriana, pela relevância do tema na agenda internacional e pela importância que os discursos, no âmbito da AGNU, têm como um indicador das diretrizes de inserção internacional dos países, a análise dos discursos na AGNU tornase um importante fator para o entendimento do que significou o desenvolvimento sustentável nos governos de Rafael Correa.

O texto a seguir apresenta uma primeira parte na qual são descritos os procedimentos metodológicos utilizados e uma segunda parte na qual os discursos são analisados, a partir dos dados quantitativos extraídos dos textos.

\section{Conteúdo dos Discursos}

Antes de se tratar do conteúdo específico dos discursos, é importante apresentar alguns conceitos que guiaram o desenvolvimento do presente texto, conceitos que envolvem tanto a preocupação com apontamentos metodológicos, como a ligação entre a política e os objetos discursivos, importante fator na construção das ideias em um discurso.

De acordo com Uwe Flick (2009), um estudo pode estabelecer abordagens diretas e quantitativas em diferentes fases do processo de investigação, não sinalizando necessariamente na redução de nenhuma das duas em importância, mas na utilização conjunta. Nesse texto, as diferentes perspectivas metodológicas, quantitativa e qualitativa, complementam-se para realizar uma análise de um tema, o processo em que você pode definir como a compreensão complementar das soluções metodológicas isoladas.

Afirma Harold Lasswell (1982), que por meio do uso do método quantitativo, o estudo do poder político pode chegar a ser entendido, o que é possível quando o idioma político é detidamente analisado. Dentro dessa linguagem política dos discursos, existem várias regras que são aplicadas com o fim de alcançar o objetivo da mensagem. Em primeiro lugar, a eficácia do que se deseja transmitir por meio do discurso e em segundo lugar, produzir vários efeitos variados como o lucro ou o poder. Estas questões não devem passar desapercebidas quando se quer extrair o significado de uma comunicação.

É nesse ponto que o método de análise do conteúdo entra em curso, pois, de acordo com Bardin (1994), este apresenta um conjunto de técnicas que se encarregam de analisar justamente os aspectos específicos da comunicação. Este método oferece uma grande quantidade de ferramentas, incluindo a análise sobre os "significados", tanto de temáticas como de palavras-chave.

Sem embargo, o método de análise de conteúdo não exclui a própria capacidade do analista em influenciar no processo de investigação. $\mathrm{O}$ uso de análise de conteúdo com o apoio de ferramentas 
de caráter quantitativo, não significa que a análise será realizada de forma mecanizada, visto que há a necessidade de interferência que pressupõe o subjetivo e o interpretativo (SILVA, RIBEIRO e CARVALHO, 2015). Sendo assim, este método atua no polo da pesquisa quantitativa e a qualitativa, provendo as ferramentas necessárias à presente análise.

Esta abordagem qualitativa e quantitativa permite também a análise dos "significantes", concentrando a observação na construção de uma palavra, na prática da língua realizada por emissores identificáveis, buscando a compreensão dos atores envolvidos em um ambiente, em um momento determinado, a partir das informações observáveis (BARDIN, 1994). Na mesma lógica, Lasswell (1982) afirma que a palavra não pode se desprender das atitudes, como por exemplo, dos gestos, que devem ser examinados em um duplo sentido entre função e linguagem. Nesse sentido, as palavras claves, os slogans, a doutrina política e o estilo do discurso não devem ser descuidados no momento da análise.

Um slogan assemelha-se a um símbolo chave e consiste em um curto encadeamento de palavras que ganham significado, graças à repetição dentro de um determinado contexto. A doutrina política refere-se às expectativas das demandas referentes às relações e práticas de poder na sociedade, ou seja, são as coisas que quando passam a fazer parte de uma relação de poder, adquirem razões que obrigam o interlocutor a legalizar a persistência da autoridade. Na linguagem da política, o estilo é uma manifestação do pensamento sobre a forma de linguagem e o conjunto das partes de uma comunicação política, a matéria que a compõe e a forma de expressão, integram uma única unidade (LASSWELL, 1982). O estilo da linguagem da política também varia de acordo com as características das situações de poder dos interlocutores e conforme as expectativas do comunicador em relação aos possíveis resultados da comunicação. Quando se presume que um resultado pode ser influenciado por uma comunicação, dedica-se mais tempo à construção de uma ideia na mensagem.

A partir dessas considerações é que os textos dos pronunciamentos do Equador na AGNU (2007-2016) são examinados a seguir. Foram coletados os dez discursos pronunciados pelos representantes do Equador, durante o Debate Geral, em cada Período de Sessão Ordinária da Assembleia Geral das Nações Unidas (AGNU), entre 2007 e $2016^{3}$. A AGNU é um dos seis principais órgãos da Organização das Nações Unidas ${ }^{4}$ (ONU) e é o único que conta com representação universal dos 193 Estados Membros. Os Estados reúnem-se anualmente em sessões ordinárias, que se iniciam

\footnotetext{
${ }^{3}$ O discurso de 2007 foi coletado no site oficial da Presidência da República do Equador. Os discursos de 2008 e 2009 foram coletados na plataforma da AGNU. A partir de 2010 os pronunciamentos estão disponíveis em um site específico. Os endereços eletrônicos de onde os documentos foram coletados encontram-se nas referências, ao final do texto.

${ }^{4}$ Os principais órgãos da ONU, todos criados em 1945 juntamente com a fundação da instituição, são: Assembleia Geral, Conselho de Segurança, Conselho Econômico e Social, Conselho de Administração Fiduciária, Corte Internacional de Justiça e a Secretaria da ONU (ONU, 2017).
} 
em setembro e seguem nos meses seguintes, com reuniões, debates e oficinas sobre os mais variados temas, envolvendo a totalidade dos órgãos da ONU. No início das sessões ordinárias ocorre o Debate Geral, marcado pelos pronunciamentos oficiais de um representante de cada Estado Membro. São esses os discursos aqui analisados.

Durante os dez anos dos governos de Rafael Correa, somente em duas oportunidades o presidente foi quem proferiu o discurso, sendo uma delas em seu primeiro ano de mandato e a outra no penúltimo ano de seu terceiro mandato. A figura 1 demonstra esses dados, podendo constatar-se que não há um padrão em relação ao ocupante de qual cargo será quem vai discursar.

\begin{tabular}{|c|l|l|}
\hline ANO & \multicolumn{1}{|c|}{ CARGO DE QUEM DISCURSOU } & \multicolumn{1}{|c|}{ NOME } \\
\hline 2007 & Presidente da República & Rafael Correa \\
\hline 2008 & Embaixadora da Missão Permanente na ONU & Maria Fernanda Espinosa \\
\hline 2009 & Ministro de Relações Exteriores & Fander Falconí \\
\hline 2010 & Vice Presidente da República & Lenín Moreno \\
\hline 2011 & Embaixador da Missão Permanente na ONU & Francisco Carrión Mena \\
\hline 2012 & Vice Ministro de Relações Exteriores e Integração Política & Marco Albuja \\
\hline 2013 & Embaixador da Missão Permanente na ONU & Xavier Lasso Mendoza \\
\hline 2014 & Vice Ministro de Relações Exteriores e Integração Política & Leonardo Arízaga \\
\hline 2015 & Presidente da República & Rafael Correa \\
\hline 2016 & Ministro de Relações Exteriores e Mobilidade Humana & Guillaume Long \\
\hline
\end{tabular}

FIGURA 1: QUADRO DOS RESPONSÁVEIS PELO PRONUNCIAMENTO NO DEBATE GERAL

FONTE: Elaborado pelos autores. Discursos do Debate Geral da AGNU.

O primeiro passo da análise dos discursos foi o de identificação dos termos mais presentes nos textos, apresentados na figura 2, considerando os dez pronunciamentos analisados. Os textos foram processados no Software Iramuteq (Interface de R pour les Analyses Multidimensionnelles de Textes et de Questionnaires). Foi inserido inicialmente um único arquivo com todos os discursos, segmentados por ano, utilizando a notação padrão do software. Posteriormente, foram inseridos os textos separadamente, segmentados por parágrafo. Esses foram os arquivos base da coleta de dados quantitativos.

Optou-se por utilizar os textos em língua espanhola e a configuração do software para a análise nesse idioma, primeiramente por conta da fidedignidade do escrito em idioma original, haja vista às implicações decorrentes de qualquer processo de tradução. Outro fator é que todos os dez pronunciamentos foram realizados oralmente em espanhol. Além disso, todos os textos analisados estão acessíveis em língua espanhola, enquanto que apenas alguns deles estão disponíveis em inglês.

Somente os discursos de 2008 e de 2009 estão disponíveis escritos em inglês, além do espanhol. O vídeo do discurso de 2007 está disponível na internet, em espanhol, no canal do site 
$Y_{\text {Ooutube }}^{5}$ da Presidência da República do Equador. Os vídeos dos discursos de 2008, de 2009, de 2013 e de 2015 estão disponíveis no site da AGNU $^{6}$ em inglês e em espanhol e os de 2012, de 2014 e de 2016 somente em inglês. Desde 2013, estão disponíveis os áudios dos discursos do Debate Geral em árabe, chinês, francês, inglês, russo e espanhol, online e para download.

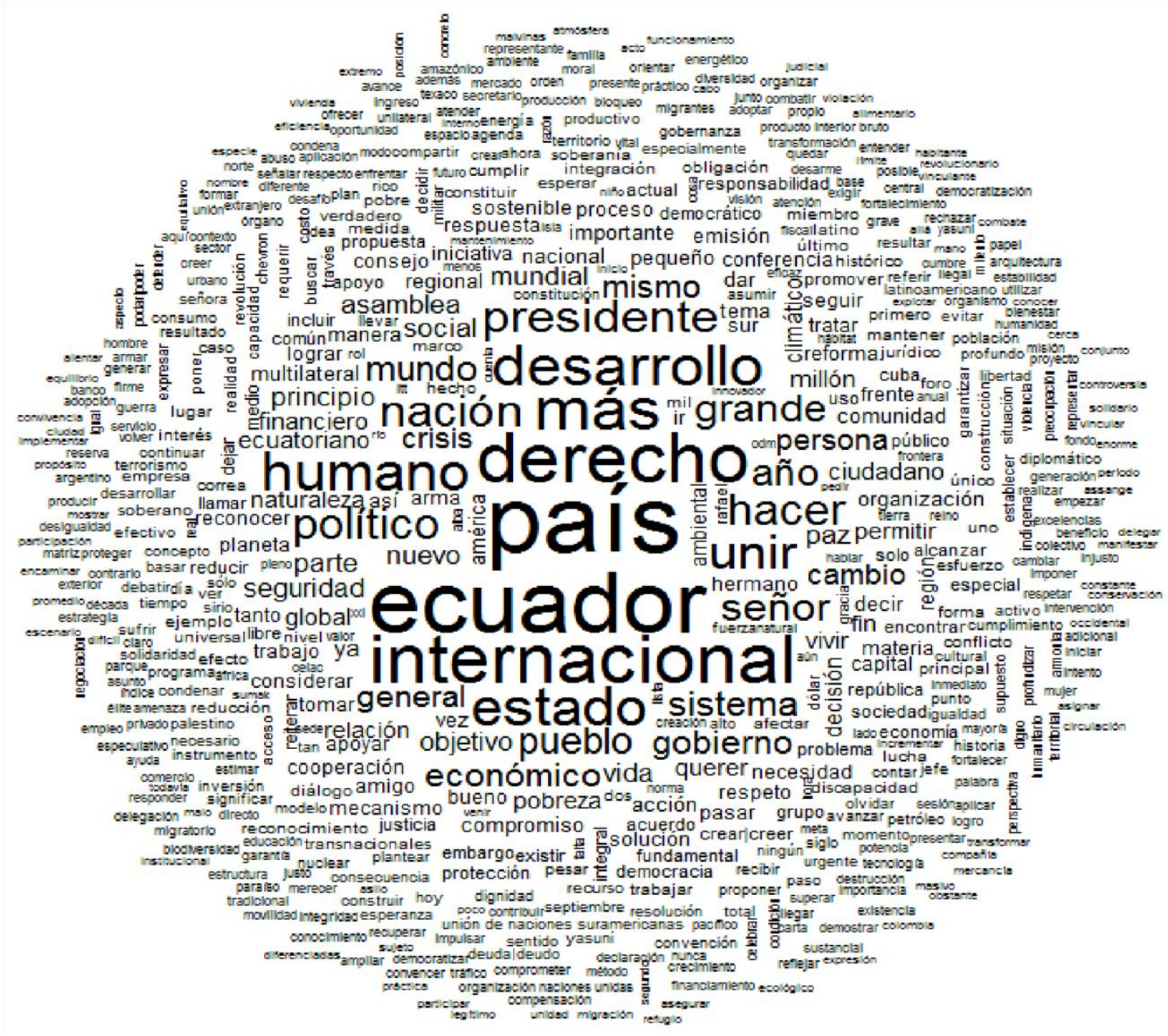

FIGURA 2: NUVEM DE PALAVRAS DOS TEXTOS ANALISADOS

FONTE: Elaborado pelos autores.

Após o primeiro levantamento de Estatística Textual, indexado ao dicionário padrão do software, foi realizada uma classificação qualitativa, eliminando-se palavras como año, Estado, señor, gobierno, mundo, ejemplo, vez, solo, mundial, nuevo, caso, idea, entre outras, por tratarem-se

\footnotetext{
${ }^{5}$ https://www.youtube.com/user/PresidenciaEc

${ }^{6}$ https://gadebate.un.org/en
} 
de termos genéricos para este tipo de documento, ou seja, qualitativamente menos relevantes. Após esta operação, foram classificadas as palavras de acordo com a incidência, gerando o quantitativo apresentado na figura 3.

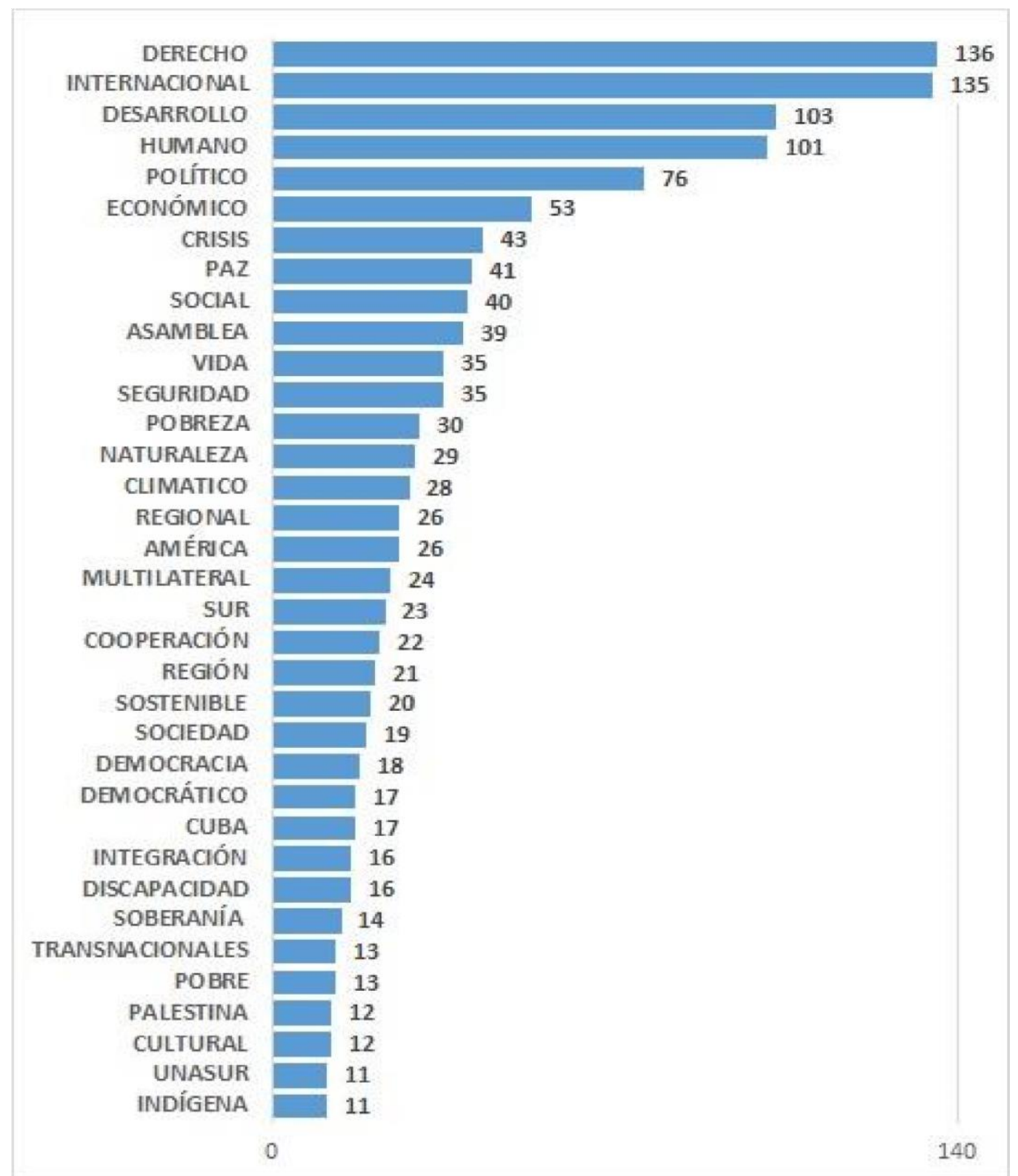

FIGURA 3: TERMOS COM MAIOR INCIDÊNCIA NOS DISCURSOS, APÓS ELIMINAÇÃO DOS TERMOS COMUNS ${ }^{7}$.

FONTE: Elaborado pelos autores.

Os termos que se destacaram após esse processo foram direito (derecho), internacional (internacional), desenvolvimento (desarrollo), humano (humano), político (político) e econômico

7 Utilizou-se a análise estatística do Iramuteq, considerando somente as formas ativas, descartando as formas suplementares. 
$(\text { económico })^{8}$. O termo sustentável (sostenible), por sua vez, apresentou-se vinte vezes. Na leitura dos discursos percebe-se - como é previsível e esperado em um discurso de um Estado em uma instância diplomática multilateral como a ONU - que o termo "internacional” foi utilizado para referir-se aos mais variados temas.

Após esta fase, foi realizada a análise de similitudes, apresentada na figura 4.

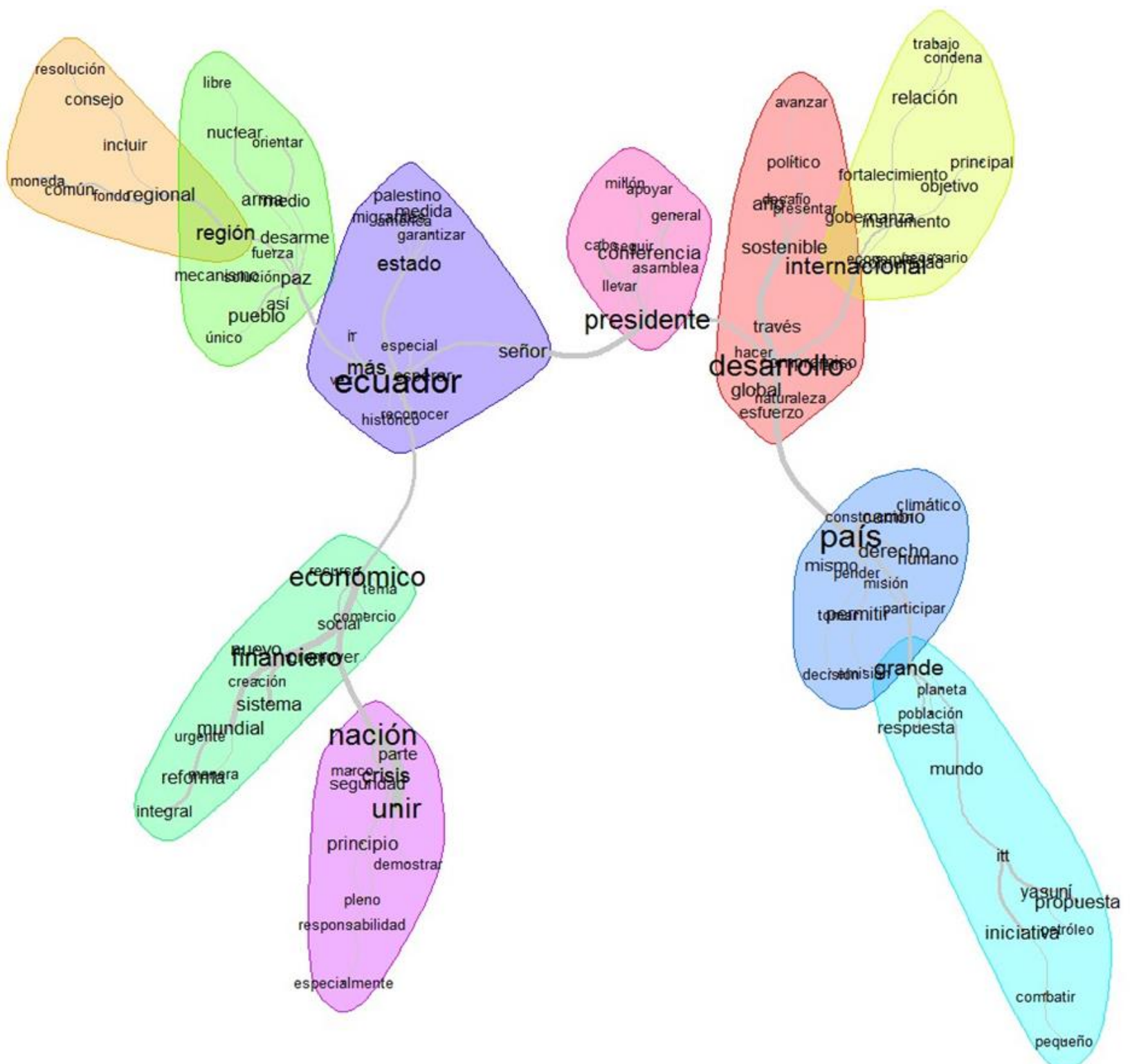

FIGURA 4: RESULTADO DA ANÁLISE DE SIMILITUDES.

FONTE: Elaborado pelos autores.

\footnotetext{
${ }^{8}$ Sobre os termos em língua espanhola, no corpo do texto, serão utilizadas as respectivas traduções em português, pois trata-se do idioma em que o artigo está escrito. Será colocado entre parênteses o termo em espanhol apenas na primeira citação do termo.
} 
Nesse ponto, é importante destacar o posicionamento de alguns termos relevantes para a análise desse artigo. As palavras desenvolvimento (desarrollo) e sustentável (sostenible) encontramse em um mesmo cluster, o mesmo ocorrendo com câmbio (cambio) e climático (climático) e também com os termos yasuní e itt. Dessa forma, o desenvolvimento sustentável, o câmbio climático e YasuníITT estão cada um em um cluster diferente, mas ocupando uma mesma parte dos textos, ligados pelo cluster onde encontra-se o câmbio climático. Apesar da distância, por exemplo, entre o desenvolvimento sustentável e Yasuní-ITT, os clusters estão próximos e ao longo dos textos analisados o câmbio climático foi utilizado tanto para abordar Yasuní-ITT como o desenvolvimento sustentável. Isso torna-se relevante se for considerado que os textos analisados têm, em média, menos de 2300 palavras, sendo textos relativamente curtos.

Após esta etapa da análise, foi possível verificar que o desenvolvimento sustentável é um dos temas de relevância no conjunto dos textos analisados. Considera-se que é um dos temas, porque ao longo do tempo analisado, outras questões apresentaram maior ou menor relevância em cada período, além da temática central deste artigo. Entretanto, a intenção desta análise quantitativa foi localizar o desenvolvimento sustentável dentro dos discursos, para posteriormente realizar a análise qualitativa, que é desenvolvida no tópico a seguir.

\section{O Desenvolvimento Sustentável nos Discursos}

Nesse tópico, analisam-se os textos verificando o sentido com o qual o desenvolvimento sustentável ${ }^{9}$ é apresentado e a quais outras temáticas está ligado, considerando que na análise de uma comunicação política, é prudente e necessário atentar-se para as modificações que ocorrem na linguagem, tais como adições de determinados termos, bem como suas omissões ou variações (LASSWELL, 1982).

Nesse sentido, é importante explicitar que, ao longo da análise dos textos, dois temas que estiveram presentes e apresentaram-se com relevantes em relação à análise do desenvolvimento sustentável. Trata-se dos termos buen vivir e sumak kawsay, que embora não estejam entre os termos mais citados nos discursos, considerando a Figura 3, ao longo da avaliação qualitativa dos textos demonstraram grande importância na construção das ideias analisadas.

Além disso, o próprio termo desenvolvimento sustentável, durante a verificação de sua presença nos pronunciamentos, foi mantido enquanto elemento de análise somente quando ambos os

\footnotetext{
${ }^{9}$ A partir desse tópico do texto, o termo desenvolvimento sustentável será utilizado sem aspas. No material gráfico produzido diretamente a partir do Iramuteq é utilizado o termo desarrollo sostenible, devido a tratar-se de material proveniente da análise do arquivo em espanhol.
} 
termos - desenvolvimento e sustentável - formam uma única ideia. Com isso, das 103 citações do termo desenvolvimento e das 20 menções ao termo sustentável, somente em 13 ocorrências considerou-se que estes formam uma unidade de análise coerente para os objetivos desse artigo.

Considerando esses elementos, esse tópico está organizado em três partes, pois considera-se que houve três fases em relação à abordagem do desenvolvimento sustentável nos discursos analisados. A Figura 5 indica as três fases que serão descritas a seguir, além da quantidade de vezes que os temas estão presentes em cada documento.

\begin{tabular}{|c|c|c|c|c|c|c|c|c|c|c|}
\cline { 2 - 13 } \multicolumn{1}{c|}{} & 2007 & 2008 & 2009 & 2010 & 2011 & 2012 & 2013 & 2014 & 2015 & 2016 \\
\hline BUEN VIVIR & 2 & 1 & 3 & 0 & 1 & 1 & 0 & 3 & 3 & 0 \\
\hline DESARROLLO SOSTENIBLE & 0 & 0 & 1 & 0 & 7 & 2 & 0 & 0 & 2 & 1 \\
\hline YASUNI ITT & 1 & 0 & 2 & 7 & 7 & 1 & 0 & 0 & 0 & 0 \\
\hline
\end{tabular}

FIGURA 5: QUANTIDADE DE OCORRÊNCIAS DOS ELEMENTOS EM ANÁLISE EM CADA DISCURSO

FONTE: Elaborado pelos autores.

\section{Buen vivir e Yasuni-ITT: a construção de uma proposta (2007-2009)}

No discurso de 2007, no qual o desenvolvimento sustentável não é explicitamente citado, é realizada uma crítica ao modelo de desenvolvimento baseado em critérios de consumo, com foco na liberalização do comércio, indicando que esta é uma alternativa paradoxal e imoral, pois ao mesmo tempo em que promove a livre circulação de mercadorias, penaliza a livre circulação de oportunidades às pessoas. Nesse pronunciamento, o primeiro de Rafael Correa em uma Assembleia Geral, o presidente afirmou que a visão equatoriana de desenvolvimento era baseada no buen vivir, na busca de paz e harmonia com a natureza, através de um modelo que pressupõe que para haver desenvolvimento, as oportunidades e potencialidades dos indivíduos também devem se ampliar (ECUADOR, 2007). Tal perspectiva, em uma primeira leitura, pode parecer que está em consonância com a ideia de Amartya Sen (2010), de que o desenvolvimento em geral, implica em um processo que em determinados momentos prioriza as questões sociais, em uma dinâmica que gera a expansão das liberdades que as pessoas desfrutam, tendo como um de seus instrumentos, entre outros elementos, a geração de oportunidades sociais como meio para o desenvolvimento de forma ampla ${ }^{10}$. Contudo, essa é uma percepção inicial que necessita ser mais bem verificada.

\footnotetext{
${ }^{10}$ O Programa das Nações Unidas para o Desenvolvimento (PNUD) não explicita a base teórica de seu conceito de desenvolvimento, mas o trabalho desenvolvido por Amartya Sen é tratado como a base do paradigma que serve de modelo para o PNUD por diversos estudos indicam tal ligação. Contudo, é importante destacar que a sustentabilidade foi tratada exteriormente ao PNUD, sendo um complemento ao paradigma de desenvolvimento humano anteriormente aplicado (MACHADO e PAMPLONA, 2008, p. 67-68).
} 
Correa destacou a proposta do país para a redução das emissões de dióxido de carbono e conservação da biodiversidade, em relação a três campos de petróleo existentes dentro do Parque Nacional Yasuni, denominadas Ishpingo, Tambococha e Tiputini, que somadas continham 920 milhões de barris de petróleo (ECUADOR, 2007), compondo cerca de $20 \%$ do total das reservas do Equador. Trata-se do projeto Yasuní-ITT, que propunha a não exploração do petróleo em tais reservas, desde que houvesse uma compensação financeira por parte da comunidade internacional (LARREA, et al., 2010).

Em 2008, assim como em 2007, o termo desenvolvimento sustentável não esteve presente no discurso equatoriano na AGNU, não havendo também nenhuma menção específica ao projeto YasuníITT. O buen vivir, por sua vez, aparece novamente no texto, assim como em 2007, realçando que tal modelo se refere à promoção de uma vida com dignidade, respeitando valores culturais e buscando a harmonia com a natureza (ECUADOR, 2008). Tanto em 2007, quanto em 2008, o tom mais crítico é voltado àquilo que é interpretado como um modelo desigual de desenvolvimento, percebido nos Objetivos do Milênio, que não produz condições mínimas de sobrevivência a todos.

No discurso de 2009, o termo desenvolvimento sustentável surge de maneira clara, havendo ainda a volta do tema Yasuní-ITT e uma maior ênfase ao buen vivir. Nesse discurso, faz-se referência ao termo Sumak Kawsay, como sinônimo de buen vivir, afirmando que "significa vivir con dignidad, de acuerdo con nuestros valores culturales y en armonía con la naturaleza, [y] es la base de las políticas económicas y sociales que está aplicando mi Gobierno para superar la inequidad social" (ECUADOR, 2009). Neste discurso, o desenvolvimento sustentável e o projeto Yasuní-ITT encontram-se dentro da mesma discussão, sobre a emergência de problemas relacionados às questões climáticas. Ao apresentar exemplos de como o Equador tem buscado soluções viáveis para este tema, indica que a principal política ambiental do país é o projeto Yasuní-ITT, além de discorrer sobre a importância da viabilização de um mecanismo financeiro para a execução do projeto. Embora tenha havido essa significativa retomada do tema de Yasuní-ITT, além do surgimento do desenvolvimento sustentável no discurso, essas questões não foram o tema central do pronunciamento, ocupando apenas $9 \%$ do espaço do discurso.

Nesse conjunto de três discursos, percebe-se a inserção do projeto Yasuní-ITT como uma bandeira do desenvolvimento sustentável por parte do Equador, que encontrou tanto uma oportunidade no âmbito da ONU, como uma limitação por conta de questões exógenas, no sentido de explorar esse discurso. A oportunidade está ligada à temática discutida em 2007 e a limitação na crise econômica mundial de 2008, que teve como marco temporal o anúncio da falência do banco de investimentos Lehman Brothers Holdings. 
Desde 2005, o presidente da Assembleia Geral, deve eleger um tema de interesse mundial, convidando os Estados Membros a focarem seus discursos nesse tema (ONU, 2017). No ano de 2007, o tema proposto foi Responding to Climate Change, o que abriu espaço para que o discurso equatoriano alçasse o projeto Yasuní-ITT como um novo modelo para a preservação dos recursos naturais, demandando o auxílio financeiro da comunidade internacional. Em 2008, a abertura do Debate Geral da AGNU ocorreu oito dias após o anúncio da quebra do Lehman Brothers, que desencadeou a crise econômica e financeira mundial, sendo este um fator externo limitante às pretensões equatorianas de ampliar a cobrança sobre os países desenvolvidos, para que contribuíssem com o projeto Yasuní-ITT. Além disso, o tema central do debate em 2008 e no ano seguinte não foram favoráveis a tal atitude. Em 2008, no estalar da crise, a temática escolhida foi The impact of the global food crisis on poverty and hunger in the world as well as the need to democratize the United Nations e em 2009, quando a maioria dos países sofria os efeitos econômicos da crise, o tema foi Effective responses to global crises: strengthening multilateralism and dialogue among civilizations for international peace, security and development.

Assim, o período compreendido entre 2007 e 2009 pode ser entendido como a fase em que o foco principal do Equador, em relação aos temas ambientais, foi o projeto Yasuní-ITT e que o buen vivir e o desenvolvimento sustentável foram temas subsidiários, que serviram para prestar apoio à ideia construída em torno do projeto Yasuní-ITT. Considerando o tempo utilizado em cada discurso para tratar dos três temas - buen vivir, Yasuní-ITT e desenvolvimento sustentável - em 2007 foi utilizado cerca de $26 \%$ do tempo, em 2008 apenas 3\% e em 2009 algo em torno de 9\% do total, conforme se verificará na Figura 7. Portanto, os três primeiros anos foram de construção da proposta, que não foi adiante por conta de elementos que estavam fora do controle equatoriano, levando a concluir que se não fossem esses eventos a ênfase poderia ter sido maior, no intuito de angariar apoio financeiro.

Na perspectiva adotada na construção das ideias no discurso de 2007 , conforme citado no início desse tópico, inicialmente identificou-se a questão do papel instrumental da geração de oportunidades sociais. Porém, considerando os discursos de 2007 a 2009 em conjunto, percebe-se a presença da perspectiva de desenvolvimento sustentável chamada por Amartya Sen de defeituosa, que é aquela da preservação do meio ambiente a partir da menor interferência possível em suas condições naturais (SEN, 2009). Embora possa ser salientado que a proposta equatoriana estivesse embasada em uma recíproca financeira por parte da comunidade internacional, destinada à melhoria das condições de vida da população, não estava claramente voltada ao uso das potencialidades do meio ambiente, de forma não destrutiva, de forma a gerar bem-estar humano. Para que isso fosse possível de ser identificado, deveria haver minimamente uma menção ao que Sen denomina de papel 
constitutivo e de papel instrumental do desenvolvimento (SEN, 2010), que permitiria realizar a ligação entre a proposta Yasuní-ITT como principal meio para um fim primordial.

\section{O projeto Yasuni-ITT como tema principal (2010-2012)}

No período de 2010 a 2012, as temáticas propostas pelos respectivos presidentes da Assembleia Geral estavam ligadas à resolução de controvérsias, mediação em conflitos e ao papel da ONU no sistema internacional. Em 2010, o tema foi reaffirming the central role of the United Nations in global governance, sendo em 2011 a discussão sobre the role of mediation in the settlement of disputes by peaceful means e em 2012 a temática foi bringing about adjustment or settlement of international disputes or situations by peaceful means. Em grande medida, os temas refletiam as preocupações da comunidade internacional com os conflitos no norte da África e Oriente Médio, conhecidos como Primavera Árabe, que tiveram início ainda em 2010 e ganharam força em 2011.

A despeito disso, os discursos equatorianos de 2010 e 2011 foram aqueles nos quais mais se deu ênfase ao projeto Yasuni-ITT, com o tema ocupando cerca de um terço do tempo destinado à intervenção realizada por Lenín Moreno em 2010, quando ocupava o cargo de vice-presidente. Moreno iniciou falando do tema através da ênfase nas mudanças climáticas, fazendo referência à importância da diversidade biológica da região amazônica - onde está localizado o Parque Nacional Yasuní - lembrando que se trata de uma reserva da biosfera, reconhecida pela UNESCO desde 1989. Destacou, também, que em Yasuní existem riquezas subterrâneas, os recursos petrolíferos, os quais o governo tinha pretensão de preservar através de uma iniciativa "que consiste en mantener, bajo tierra, sin explotar, ese petróleo” (ECUADOR, 2010). Informou, ainda, que havia sido criado um fundo administrado pelo PNUD, com aportes financeiros do Estado equatoriano, para o qual eram convocados, nesse pronunciamento, todos os países do mundo a se tornarem contribuintes, principalmente as nações industrializadas. Houve destaque na questão de Yasuní no discurso, mas o buen vivir e o desenvolvimento sustentável não foram mencionados diretamente.

Em 2011, Yasuní seguiu sendo um tema relevante e o desenvolvimento sustentável também ocupou grande parte do discurso. Porém, apesar do buen vivir ter sido citado uma única vez, ocorreu o atrelamento direto do buen vivir com o desenvolvimento sustentável. Ao referir-se à conferência Rio+20, o discurso enfatiza que diversos objetivos da Convenção do Rio, de 1992, ainda se encontravam pendentes, realçando que um compromisso político com o desenvolvimento sustentável requer medidas em três pilares: econômico, social e ambiental (ECUADOR, 2011). Articulando esses pilares com o desenvolvimento sustentável, afirma que era necessário:

Articular los instrumentos internacionales en el ámbito del desarrollo sostenible para lograr una equidad, no solo con las propuestas de una economía verde o el 
fortalecimiento del marco institucional, sino con la incorporación del desarrollo hacia la integralidad de mejorar la calidad de vida con una adecuada interrelación entre los tres pilares, lo que el Ecuador llama "buen vivir" (ECUADOR, 2011).

Nesse ponto, pode-se considerar que a ideia de buen vivir é construída de uma forma que não está desligada de outras perspectivas sobre o tema, tal como a discussão de Sen, ao referir-se ao desenvolvimento sustentável e ao meio ambiente natural, quando afirma que environmental sustainability has typically been defined in terms of the preservation and enhancement of the quality of human life (SEN, 2009) e em seguida exalta o Relatório Bruntland ${ }^{11}$ por ter promovido a compreensão de que o valor do meio ambiente não pode ser dissociado das vidas dos seres vivos.

Ainda no discurso de 2011, denominada como uma proposta visionária para o desenvolvimento sustentável, a iniciativa Yasuní-ITT ocupou também importante parte do discurso do embaixador Carrion Mena. No entanto, a maioria das informações foram as mesmas anteriormente citadas nos discursos de 2007, 2009 e 2010. O que houve de diferente foi a informação de que o Equador havia recebido apoio de diversos países, além de aportes financeiros individuais e do setor privado (ECUADOR, 2011). Além disso, anunciou-se que o Equador passaria a trabalhar a partir de uma proposta mais ampla, complementar ao projeto Yasuní-ITT, conhecida como Emisiones Netas Evitadas, que se trata de um mecanismo de mercado voltado para a redução da emissão de carbono na atmosfera, a partir do qual os países em desenvolvimento seriam compensados pelos países desenvolvidos, caso não emitissem determinada quantidade de dióxido de carbono que teriam emitido, se utilizassem toda a sua capacidade econômica e industrial (ORTEGA, VERGARA e REYES, 2011). Assim, o discurso de 2011, pela presença do desenvolvimento sustentável, pela apresentação clara dos pilares do buen vivir e pela ênfase ao projeto Yasuní-ITT, marcou um importante momento no posicionamento do Equador perante a comunidade internacional, em relação ao desenvolvimento sustentável.

No discurso de 2012 foi reduzida a ênfase sobre o desenvolvimento sustentável e o buen vivir, bem como o tipo de abordagem, em relação aos anos anteriores. Sobre o buen vivir, apresentou-se uma crítica ao que foi chamado de modelo arcaico de Estado de Direito, referindo-se que tal ideia é obsoleta e inaplicável nos tempos atuais, visto que se trata de um conjunto de normas que foram escritas e pensadas em outro momento da História (ECUADOR, 2012). Afirma que a perspectiva da Constituição equatoriana de 2008 é de um Estado de Direitos e Garantias, baseado nas premissas do

\footnotetext{
${ }^{11}$ O relatório Brundtland, também conhecido pelo título Nosso Futuro Comum, é um documento anexado ao Report of the World Comission on Environment and Development (ONU, 1987), elaborado por uma comissão chefiada pela diplomata norueguesa Gro Harlem Brundtland. Foi nesse documento que se apresentou a definição de desenvolvimento sustentável como "aquele que atende as necessidades do presente sem comprometer as possibilidades de as gerações futuras atenderem suas próprias necessidades".
} 
buen vivir. Sobre o desenvolvimento sustentável, cita a iniciativa Yasuní-ITT e o mecanismo de Emisiones Netas Evitadas, como principais projetos do país em matéria de políticas de sustentabilidade ambiental. $\mathrm{O}$ discurso afirma que o Equador propôs um modelo de desenvolvimento participativo, mas que tem observado pouca vontade política, por parte dos Estados, para sujeitaremse a compromissos juridicamente vinculantes para a redução de emissões de carbono na atmosfera (ECUADOR, 2012). Nesse sentido, é marcante que nos anos anteriores tenha sido realizado um apelo para a participação dos países desenvolvidos e posteriormente tenha sido informado que havia a participação de atores privados, mas não de entes estatais no apoio financeiro ao projeto Yasuní-ITT. A asseveração da crítica pela não participação e a redução da importância das temáticas de Yasuní e do desenvolvimento sustentável, marcam a fase do declínio do tema nos pronunciamentos.

As figuras 6 e 7, a seguir, demonstram a variação da ênfase no desenvolvimento sustentável, no buen vivir e no projeto Yasuní-ITT ao longo dos dez anos, considerando o número de vezes em que os termos são citados e também o espaço ocupado pela discussão dentro do discurso.

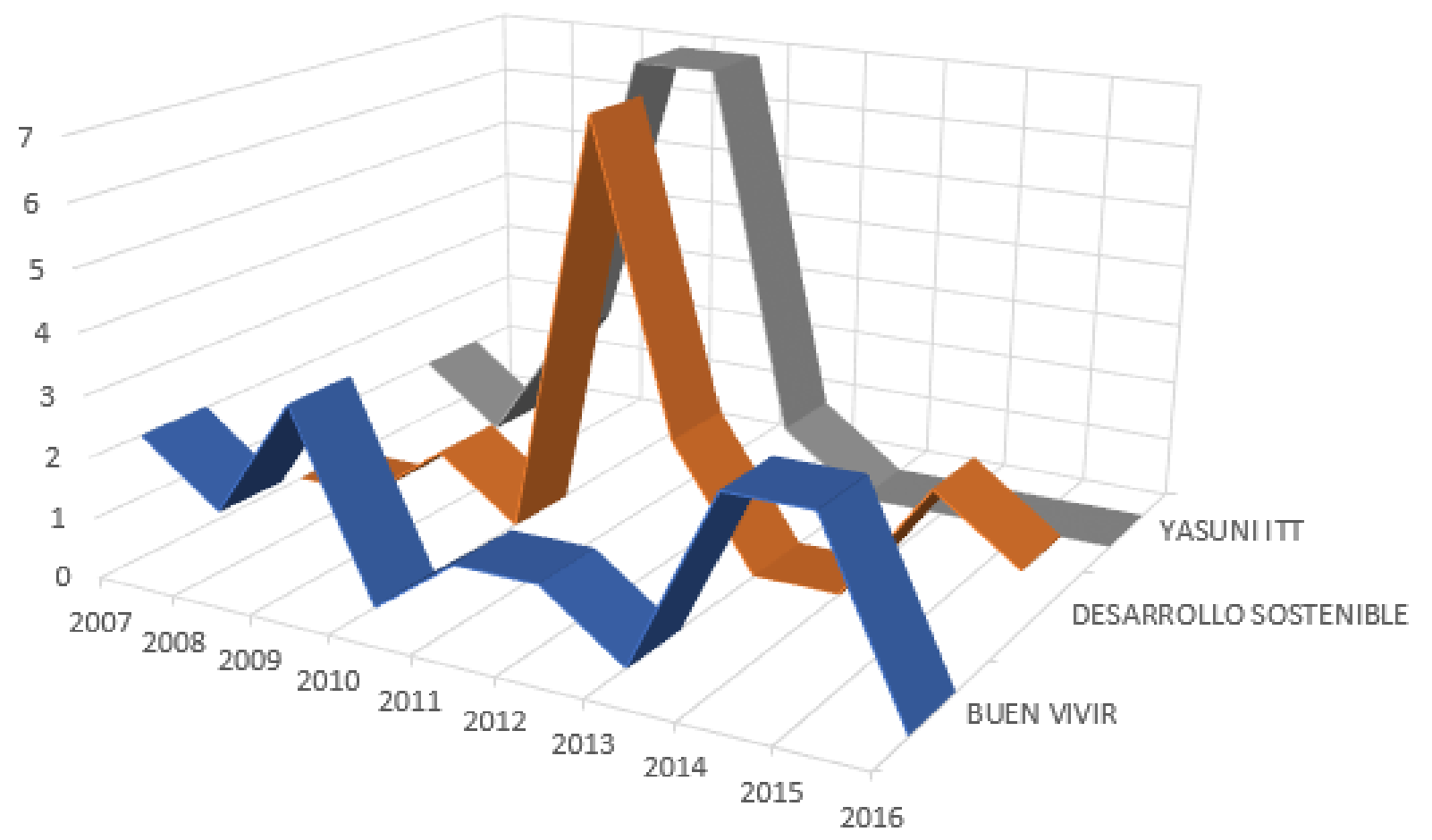

FIGURA 6: VARIAÇÃO DA QUANTIDADE ABSOLUTA QUE CADA TERMO ESTEVE PRESENTE EM CADA UM NOS DISCURSOS

FONTE: Elaborado pelos autores.

Para a obtenção dos dados das figuras 6 e 7, os textos dos discursos foram submetidos separadamente à análise de Estatística Textual, analisando-se quantitativamente por seções textuais. 


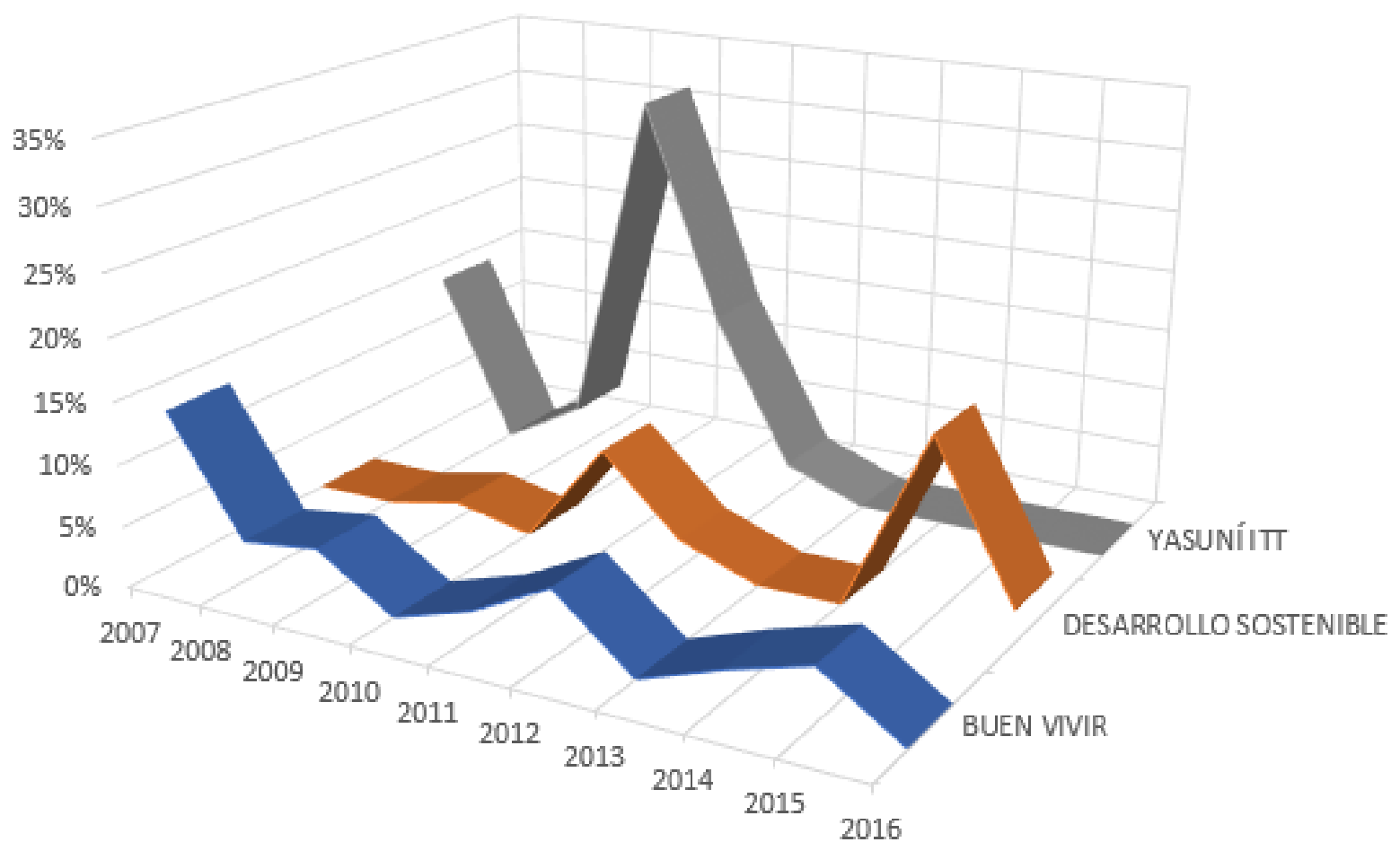

FIGURA 7: VARIAÇÃO DO ESPAÇO OCUPADO PELOS TEMAS EM CONJUNTO, NO TOTAL DO DISCURSO FONTE: Elaborado pelos autores.

Nas duas figuras acima, fica perceptível o destaque aos anos 2010 e 2011 e o início de um declínio em 2012, declínio este que foi definitivo para a presença de Yasuní-ITT nos pronunciamentos. Em 2010, quando o desenvolvimento sustentável e o buen vivir não foram mencionados, somente Yasuní-ITT foi discutido em 32\% do espaço do discurso. Em 2011, os três temas em conjunto utilizaram 25\% do espaço do discurso e em 2012 esse número caiu para 10\%, considerando os três termos analisados. Deve-se destacar que em 2011 tanto Yasuní-ITT como desenvolvimento sustentável foram citados o mesmo número de vezes no discurso, sete vezes cada um, mas enquanto isso significou o uso de $14 \%$ do espaço do discurso para Yasuní-ITT, para o desenvolvimento sustentável foi de apenas $8,4 \%$.

Até esse ponto o desenvolvimento sustentável discursado pelo Equador, enquanto ideia geral, seguiu muito próximo do conceito da busca de uma combinação de fatores sociais, ambientais, ecológicos e econômicos, sendo que as atividades econômicas deveriam estar voltadas à apropriação e transformação da natureza em benefício das necessidades humanas, considerando a garantia de recursos para as gerações futuras (CARVALHO, 2017, p. 129). Todavia, o tom do discurso de 2012, se comparado aos dois anos imediatamente anteriores, bem como a ausência total do tema no discurso de 2013 eram indicativos de que a justificativa central da abordagem do desenvolvimento sustentável 
poderia não mudar, mas a linha guia da construção da ideia dava indicativos de que seria alterada nos discursos do Equador.

\section{Retomada do discurso do buen vivir (2014-2016)}

A mudança do viés sobre o desenvolvimento sustentável após 2012 foi significativa, tanto que no ano seguinte, em 2013, o buen vivir e o desenvolvimento sustentável não estiveram no discurso da AGNU. O projeto Yasuní-ITT apareceu pela última vez em 2012, não estando presente em nenhum dos discursos seguintes, na AGNU, do período de governo de Rafael Correa. A maior parte do discurso equatoriano de 2013 esteve em diálogo com o tema escolhido naquele ano, que foi the way forward: a disability-inclusive development agenda towards 2015 and beyond. Essa mudança é a manifestação do que indicam Hamel e Wentz, que "de todos os aspectos envolvidos no desenvolvimento sustentável, o ambiental é o mais controvertido" (HAMEL e WENTZ, 2017), mas que o discurso desse tema busca um consenso e uma solidariedade, em âmbito local e internacional, o que no caso equatoriano não obteve suvcesso.

Em 2014, somente o buen vivir e seu respectivo conceito em idioma indígena, Sumak Kawsay, apareceram no discurso. Em relação ao Sumak Kawsay, sobre o qual o texto destaca que "en el lenguaje de nuestros pueblos ancestrales significa Buen Vivir" (ECUADOR, 2014), percebe-se que é realizada a construção de uma ligação entre este tema e o modelo de governo adotado desde 2007 no Equador, a Revolución Ciudadana, que por sua vez é colocada em acordo com os Objetivos do Milênio e com a agenda pós 2015 das Nações Unidas (ECUADOR, 2014). Nota-se que tal afirmativa é diferente do conteúdo dos primeiros discursos da gestão Correa, quando os Objetivos do Milênio eram tratados como um modelo excludente e que a ideia de buen vivir era uma alternativa a essa perspectiva. Essa é uma mudança substancial, se considerado que a questão do desenvolvimento estava ligada fortemente à temática central proposta por Sam Kutesa, presidente da Assembleia Geral naquele ano, que sugeriu que a discussão estivesse centrada em Delivering on and Implementing $a$ Transformative Post-2015 Development Agenda.

Outro ponto importante é que não é feita referência ao desenvolvimento sustentável na parte do discurso na qual são abordadas as mudanças climáticas, havendo ainda certa ênfase em um desenvolvimento endógeno, a partir da mudança da matriz produtiva, através da dinamização do desenvolvimento produtivo, com aumento dos fluxos de comércio e do investimento estrangeiro direto. Além da citação desses modelos de desenvolvimento - endógeno e produtivo - o discurso faz referência ao desenvolvimento urbano sustentável, por conta da definição do Equador como sede da Conferência Habitat III, em 2016. 
Em 2015, ano em que a ONU completou sete décadas de existência, a temática para discussão foi The United Nations at 70 - A New Commitment to Action. No discurso de 2015 do Equador, o buen vivir foi indicado como modelo para alcançar os 17 Objetivos do Desenvolvimento Sustentável, apontando que tais objetivos estão baseados em promover padrões mínimos de vida, enquanto que o buen vivir acena para um máximo de condições sociais, ao invés da mínima condição de vida (ECUADOR, 2015). Em um tópico específico sobre as mudanças climáticas, o discurso constrói a ideia de que é necessário o desenvolvimento sustentável, listando a seguir diversos problemas decorrentes da emissão de poluentes e de outras práticas mundiais ambientalmente prejudiciais, finalizando tal parte do discurso com a afirmativa de que:

es necesario caminar hacia una Declaración Universal de los Derechos de la Naturaleza. El principal derecho universal de la naturaleza debería ser el que pueda seguir existiendo, pero, también, que pueda seguir ofreciendo los medios de vida necesarios para que nuestras sociedades puedan vivir con el Sumak Kawsay (ECUADOR, 2015).

No último discurso equatoriano na Assembleia Geral durante o período Correa, o desenvolvimento sustentável foi citado uma única vez, mas sem ligação com questões ambientais ou relacionadas ao buen vivir, estando dentro de uma discussão mais ampla sobre desenvolvimento. Neste discurso, destacou-se que, historicamente, as regiões mais pobres e desiguais do mundo, tal como a América Latina, têm sido influenciadas a seguir uma mesma receita para obter o desenvolvimento, receita na qual o conceito de desenvolvimento é tratado de forma técnica. O discurso aponta que os países da periferia devem "disputar" o conceito de desenvolvimento, pois não se trata de um conceito técnico, mas de um fenômeno político. Afirma que:

En América Latina, la región más desigual del mundo, no puede haber verdadero desarrollo sostenible, con cohesión social y estabilidad política- sin redistribución. $Y$ esa redistribución muchas veces significa entrar en conflicto con élites que se han opuesto históricamente y se siguen oponiendo en la actualidad, a ceder cualquier ápice de su poder político (ECUADOR, 2016).

O trecho citado exemplifica a tônica do discurso que, no que tange ao desenvolvimento, seguiu a linha da crítica ao que denominou de paradigma do fundamentalismo ideológico neoliberal. É notável que o Equador tenha concedido menos espaço ao desenvolvimento sustentável nesse discurso do que no ano anterior, pois em 2015 as temáticas relacionadas ao desenvolvimento sustentável ocuparam 19\% do espaço do discurso, tendo reduzido para 2,6\% em 2016, ano no qual o tema de discussão foi The Sustainable Development Goals: A Universal Push to Transform our World. 
Em relação ao período de 2013 a 2015, há que se destacar dois pontos. Um deles é a ausência do projeto Yasuní-ITT, por conta da determinação do fim do projeto, em 15 de agosto de 2013, anunciado em um pronunciamento do presidente Rafael Correa à nação equatoriana ${ }^{12}$. Na ocasião, Correa declarou que um dos motivos do fracasso da iniciativa foi a coincidência temporal com a crise econômica, mas que a razão principal foi a hipocrisia dos países desenvolvidos em não apoiar iniciativas como essa, sendo eles os maiores poluidores, ao mesmo tempo em que discursam sobre a necessidade de preservação do meio ambiente. $\mathrm{O}$ segundo ponto a se relevar, é a retomada da ênfase no buen vivir em 2014 e 2015, com ênfase nos mesmos elementos apontados em anos anteriores, da relação com a natureza e da possibilidade do buen vivir servir como modelo de desenvolvimento. No entanto, diferente dos primeiros anos dos governos Correa, quando o posicionamento era crítico em relação aos modelos de desenvolvimento, nos últimos anos o tom do discurso altera-se para a crítica às desigualdades.

A alteração no eixo da apresentação da ideia de desenvolvimento sustentável por parte do Equador, após o abandono do projeto Yasuní-ITT, não se aproxima da formulação de Amartya Sen, a partir da qual "if the importance of human lives lies not merely in our living standard and needfulfilment, but also in the freedom that we enjoy, then the idea of sustainable development has to be correspondingly reformulated" (SEN, 2009). Considerando os argumentos e o caminho utilizados nessa análise, verifica-se que tal mudança de perspectiva teve um caráter muito mais instrumental do que voltado a uma diferente percepção ética. Da mesma forma, conclui-se que é uma atitude instrumental muito mais discursiva do que prática, se for considerado que o papel instrumental da liberdade que o desenvolvimento deve produzir aos seres humanos, deve envolver a geração de oportunidades sociais e facilidades econômicas (SEN, 2010).

É inegável que o discurso e a ideia do buen vivir apresentam um novo modelo de organização social, política e econômica, fugindo da tradicional definição linear de desenvolvimento, buscando um modelo libertador, que respeita a dignidade humana, preconizando outras vias para o desenvolvimento (CAOVILLA, ZANCO e SIMES, 2017). No entanto, o acompanhamento dos desdobramentos dos discursos equatorianos na AGNU apontou limites a essa perspectiva, o que a torna não tão libertadora assim. Fica evidente que é importante matizar os diferentes momentos em que o discurso, a ideia ou a defesa do desenvolvimento sustentável surgem dentro da prática política discursiva.

\footnotetext{
${ }^{12}$ Disponível em https://www.youtube.com/watch?v=3qzW2TdiYtc
} 


\section{Considerações Finais}

Considerando o objetivo principal do texto, de verificar como o desenvolvimento sustentável foi apresentado nos discursos do Equador na AGNU, entre 2007 e 2016, chega-se a duas conclusões. A primeira delas é que o projeto Yasuní-ITT foi o protagonista entre 2007 e 2012, quando as questões do desenvolvimento sustentável e as demais a ela atreladas - meio ambiente, mudanças climáticas, entre outras - foram tema dos discursos. A segunda conclusão é a de que houve, nesses dez anos, três períodos nos quais o desenvolvimento sustentável teve diferentes ênfases nos discursos.

Em relação ao projeto Yasuní-ITT, presente desde o discurso de 2007, verificou-se que se tratava da principal bandeira do presidente Rafael Correa em questões ambientais, mas que necessitava de uma contraparte financeira da comunidade internacional, o que não aconteceu. Conforme o próprio Rafael Correa declarou em 2013, quando anunciou o fím do projeto, primeiramente o projeto não foi adiante por conta do timing em que foi lançado, que coincidiu com a crise econômica global de 2008. Em segundo lugar, não houve o apoio financeiro esperado, por parte dos países industrializados.

Sobre a conclusão de que o desenvolvimento sustentável teve três distintos momentos nos discursos equatorianos, deve-se considerar que tais momentos tiveram também o projeto Yasuní-ITT como fator determinante. No primeiro período, de 2007 a 2009, houve a tentativa de construção de uma ideia baseada no projeto, mas que foi limitada principalmente pela crise econômica. No segundo momento, de 2010 a 2012, houve uma grande ênfase em relação ao projeto Yasuní-ITT em 2010 e 2011, com menor ênfase e um tom de decepção na construção do discurso, em 2012. O terceiro período, após 2012, foi quando o projeto sequer foi mencionado e o discurso resgatou as questões relacionadas ao buen vivir e ao Sumak Kawsay para referir-se ao desenvolvimento sustentável e demais temas relacionados.

Contudo, isso não significa que o buen vivir estivesse fora dos discursos nos períodos anteriores. Observou-se que o buen vivir ou seu congênere em língua indígena, o Sumak Kawsay, estiveram presentes em oito dos dez discursos. Esse tema ficou de fora apenas no discurso de 2010, quando o desenvolvimento sustentável e Yasuní-ITT protagonizaram o discurso, e em 2013, ano do fim do projeto Yasuní-ITT, quando nenhum desses temas esteve presente no discurso.

As informações extraídas e discutidas possuem ainda diversas possibilidades de encaminhamentos dos mais variados tipos de análises, assim como os próprios elementos textuais, significados e significantes que não foram explorados, podem ser objeto de novas análises. Este texto desenvolveu-se com um caráter muito mais exploratório do que analítico, mas permitiu captar diversas nuances da construção de cada discurso e também do conjunto dos discursos explorados, que 
claramente construíram o histórico da apresentação da visão equatoriana de governo sustentável durante os governos de Rafael Correa.

Finalmente, deve-se pontuar que a abordagem desse texto permitiu verificar como os discursos no âmbito da AGNU são utilizados como instrumento político e como palco para construção e disseminação de ideias. No entanto, também foi possível perceber que as questões conjunturais e as possíveis limitações econômicas não devem ser negligenciadas quando é traçada uma estratégia política que depende do ambiente internacional. Todavia, ainda que sejam considerados tais fatores, haverá a incerteza do sucesso, visto que o ambiente econômico é volátil, as conjunturas são flexíveis e o ambiente político complexo.

\section{Referências}

BARDIN, L. Análise de Conteúdo. Tradução de Luís Antero Reto e Augusto Pinheiro. São Paulo: Edições 70, 1994.

CAOVILLA, M. A. L.; ZANCO, A.; SIMES, V. D. Bem viver: possibilidades e contornos viáveis à construção de outro paradigma de desenvolvimento econômico e social na América Latina. In: ZAMBAM, J. N.; KAMPHORST, M. A. Estudos sobre Amartya Sen: justiça, liberdade e desenvolvimento. Porto Alegre: Fi, v. 2, 2017. p. 317-332.

CARVALHO, S. A. D. Políticas públicas ambientais e desigualdades sociais: paradoxos de processos de governança. In: ZAMBAM, N. J.; KUJAWA, H. A. Estudos sobre Amartya Sen: políticas públicas, capabilities e desenvolvimento. Porto Alegre: Fi, v. 1, 2017. p. 121-148.

ECUADOR. Discurso del Presidente en la 62 ${ }^{a}$ Asamblea General de las Naciones Unidas. Quito: Presidencia de la República del Ecuador, 2007. Disponivel em: <http://www.presidencia.gob.ec/wpcontent/uploads/downloads/2013/10/2007-09-25-Discurso-del-Presidente-en-la-62-AsambleaGeneral-de-las-Naciones-Unidas.pdf>. Acesso em: 15 ago 2017.

ECUADOR. Intervención de la Embajadora Maria Fernanda Espinosa - 63 $^{\circ}$ Período de Sesiones de la AGNU. New York: Misión Permanente ante las Naciones Unidas, 2008. Disponivel em: 〈http://www.un.org/en/ga/63/generaldebate/pdf/ecuador_es.pdf〉. Acesso em: 15 ago 2017.

ECUADOR. Constitución de la República del Ecuador. Quito: Asamblea Constituyente, 2008b. Disponivel em: <http://www.asambleanacional.gov.ec/documentos/constitucion_de_bolsillo.pdf>. Acesso em: 8 mai 2017.

ECUADOR. Intervención del Señor Ministro de Relaciones Exteriores Dr. Fander Falconi. New York: Misión Permanente ante las Naciones Unidas, 2009. Disponivel em: <https://gadebate.un.org/sites/default/files/gastatements/64/64_EC_es.pdf>. Acesso em: 15 ago 2017. 
ECUADOR. Intervención S.E. Sr. Lenín Moreno Garcés - $\mathbf{6 5}^{\circ}$ Periodo de Sesiones Asamblea General de las Naciones Unidas. Quito: Ministerio de Relaciones Exteriores Comercio e Integración, 2010. Disponivel em:

<https://gadebate.un.org/sites/default/files/gastatements/65/65\%20EC_es.pdf>. Acesso em: 15 ago 2017.

ECUADOR. Intervención del Embajador Francisco Carrion Mena - Debate General del $\mathbf{6 6}^{\circ}$ Periodo de Sesines de la AGNU. New York: Misión Permanente ante las Naciones Unidas, 2011. Disponivel em: <https://gadebate.un.org/sites/default/files/gastatements/66/EC_es.pdf >. Acesso em: 15 ago 2017.

ECUADOR. Intervencion del Excelentisimo Señor Viceministro de Relaciones Exteriores e Integracion Politica de La República del Ecuador Dr. Marco Albuja - $67^{\circ}$ Periodo de Sesiones de La AGNU. Quito: Ministerio de Relaciones Exteriores e Integracion Politica, 2012. Disponivel em: <https://gadebate.un.org/sites/default/files/gastatements/67/EC_es.pdf>. Acesso em: 15 ago 2017.

ECUADOR. Intervención del Viceministro de Relaciones Exteriores e Integración Política Leonardo Arízaga - 69 ${ }^{\circ}$ Periodo de Sesiones de la AGNU. Quito: Ministerio Relaciones Exteriores e Integración Política, 2014. Disponivel em:

<https://gadebate.un.org/sites/default/files/gastatements/69/EC_es.pdf>. Acesso em: 15 ago 2017.

ECUADOR. Intervención del Presidente de la República del Ecuador, Rafael Correa Delgado, durante el Debate General del $7^{\circ}$ Período de Sesiones de las Naciones Unidas. Quito: Presidéncia de la República, 2015. Disponivel em:

<https://gadebate.un.org/sites/default/files/gastatements/70/70_EC_es_3.pdf>. Acesso em: 15 ago 2017.

ECUADOR. Discurso del Dr. Guillaume Long, Ministro de Relaciones Exteriores y Movilidad Humana - Debate General de la 71 ${ }^{a}$ AGNU. Quito: Ministerio de Relaciones Exteriores y Movilidad Humana, 2016. Disponivel em:

<https://gadebate.un.org/sites/default/files/gastatements/71/71_EC_es.pdf>. Acesso em: 15 ago 2017.

FLICK, U. Introdução à pesquisa qualitativa. Tradução de Joice Elias Costa. 3. ed. Porto Alegre: Artmed, 2009.

HAMEL, E. H.; WENTZ, G. Como o desenvolvimento sustentável das comunidades rurais pode (e deve) auxiliar na redução das desigualdades. Uma discussão a partir dos ideais do desenvolvimento como liberdade? In: ZAMBAM, N. J.; KAMPHORST, M. A. Estudos sobre Amartya Sen: justiça, liberdade e desenvolvimento. Porto Alegre: Fi, v. 2, 2017. p. 67-92.

HANDL, G. Declaration of the United Nations Conference on the Human Environment (Stockolm Decaration), 1972 and the Rio Declaration on Environment and Development, 1992. United Nations Audivisual Library of International Law, New York, 2012.

LARREA, C. et al. Yasuní-ITT: una iniciativa para cambiar la Historia. Quito: Universidad Andina Simón Bolívar, 2010.

LASSWELL, H. D. A linguagem da política. Tradução de Lúcia Dauster Vivacqua e Silva e Sônia de Castro Neves. Brasília: UnB, 1982. 
MACHADO, J. G. R.; PAMPLONA, J. B. A ONU e o desenvolvimento econômico: uma interpretação das bases teóricas da atuação do PNUD. Economia e Sociedade, Campinas, 17, n. 1, abr 2008. 53-84.

ONU. Our Common Future. Report of the World Commission on Environment and Development, New York, 1987.

ONU. United Nations, 2017. Disponivel em: <http://www.un.org/es/sections/about-un/mainorgans/index.html>. Acesso em: 11 out 2017.

ORTEGA, D.; VERGARA, A.; REYES, A. Emisiones netas evitadas: ENE. Una propuesta para el Buen Vivir. Quito: Ministerio de Relaciones Exteriores, Comercio e Integración del Ecuador, 2011.

SEN, A. K. The idea of justice. Cambridge: Harvard University Press, 2009.

SEN, A. K. Desenvolvimento como liberdade. Tradução de Laura Teixeira Motta. São Paulo: Companhia das Letras, 2010.

SILVA, D. C. D.; RIBEIRO, R. A.; CARVAlHO, T. C. D. O. A análise de conteúdo de pronunciamento oficiais como metodologia interpretativa da política externa brasileira. Revista Eletrônica de Ciência Política, v. 6, n. 2, 2015. 